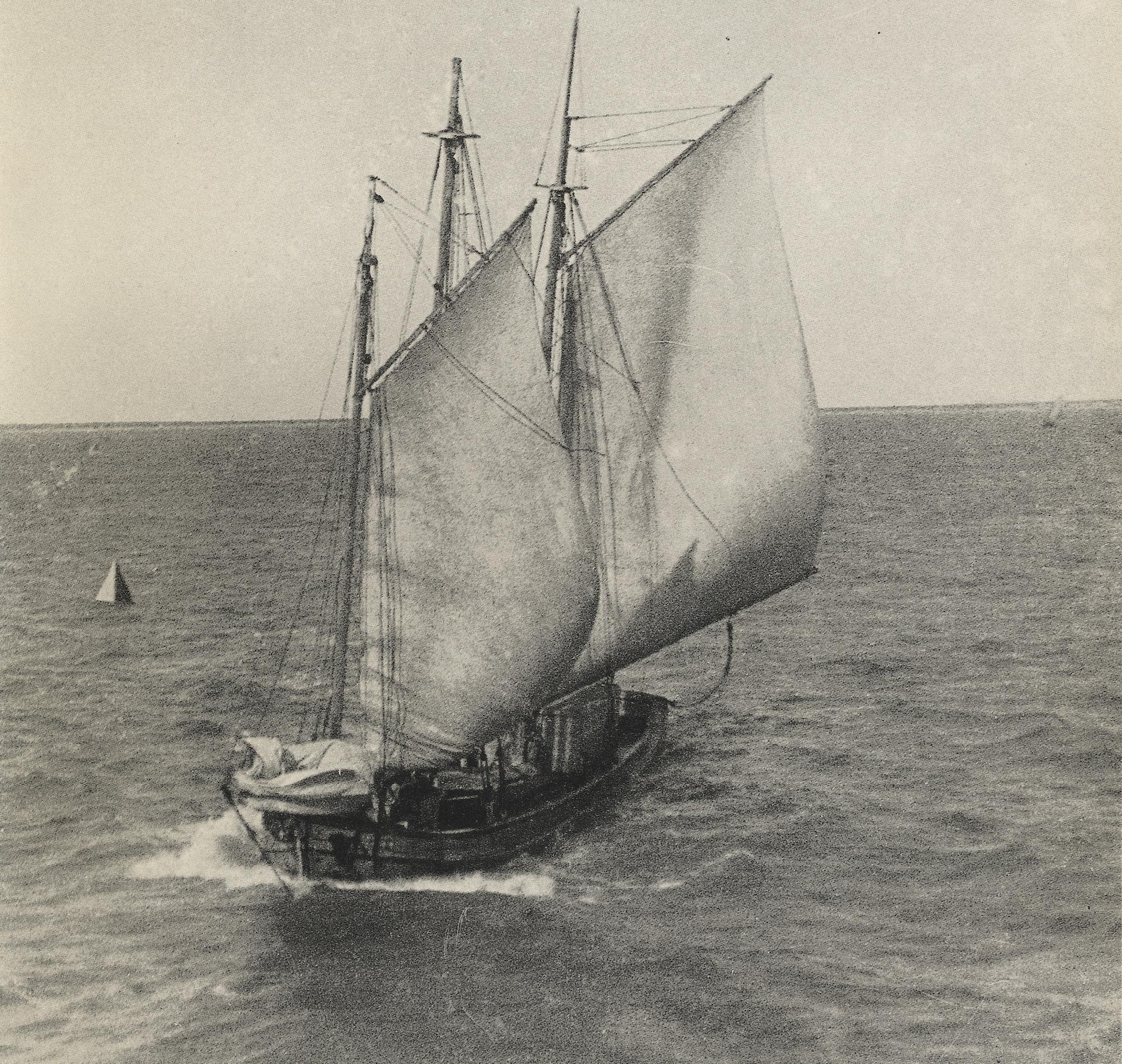




\section{PAISAGENS CULTURAIS NO BRASIL: UM DESAFIO PENDENTE}

\section{Adelita Araujo}

Advogada e arquiteta. Mestre em Urbanismo, atualmente aluna do Programa de Doutorado em Urbanismo da Puc-Campinas e Doutorado Sanduíche no Programa de Urbanismo e Ordenação do Território da Universidade Politécnica da Catalunha

\section{Joaquín Sabaté}

Dr. arquiteto e economista. Professor de urbanismo na Universidade Politécnica da Catalunha. Coordenador do Laboratório Internacional de Paisagens Culturais e editor da revista Identidades

\section{EVOLUÇÃO DO CONCEITO DE PATRIMÔNIO}

Aideia de conservar o patrimônio herdado de gerações anteriores é relativamente moderna. De fato, até o século XIX as diferentes etapas na construção da cidade implicam na sobreposição de distintos tecidos, e geralmente a paulatina substituição daqueles mais antigos. As melhores realizações do renascimento e do barroco europeu, ainda que manifestando uma altíssima preocupação com a forma urbana, frequentemente fazem tábua rasa da cidade herdada.

As primeiras medidas efetivas para preservação de edifícios nascem na cidade de Paris, posicionada como o coração de uma Europa com grandes capitais, onde se cria em 1834 a Inspeção Geral de Monumentos Históricos. Quando o escritor Prosper Mérimée assume o

considerando sua antiguidade e certas preferências estilísticas que se modificam ao longo do tempo e da ação de sucessivos responsáveis. 
No começo do século XIX o Brasil vive um momento de grandes mudanças políticas que se refletem nas suas concepções sobre o patrimônio. Trata-se do período da chegada da corte portuguesa, quando o país imerge dentro da cultura europeia redefinindo conceitos e valores estéticos. Mas é também um momento de reconhecimento, descoberta e documentação da cultura, destacando-se a contribuição dos inúmeros viajantes estrangeiros, especialmente franceses, que chegam ao Brasil para vislumbrar o "novo mundo" e produzir expedições que resultam em verdadeiras missões científicas de exploração do território. Destaca-se a importância de viajantes como Carl Friedrich von Martius, Johann Baptist von Spix e Auguste Saint-Hilaire, e de pintores como Jean-Baptist Debret e Johann Moritz Rugendas, que através de suas obras registram a beleza e a riqueza do país, em temas que tratam da arquitetura, dos modos de vida, da população, das riquezas naturais, das culturas e das paisagens.

Na Europa a preocupação com o patrimônio se consolida juntamente com os dinâmicos processos de transformação vinculados a revolução industrial. As principais cidades criam recintos para conservar e expor manifestações patrimoniais diversas, tanto naturais quanto culturais (parques zoológicos, jardins botânicos, grandes museus folclóricos, etnográficos y arqueológicos...). O objetivo comum é preservar determinadas peças e generalizar o acesso e o desfrute público através dos museus, o que produz de imediato a desvinculação do patrimônio com seu território original.

Em meados do século XIX aparecem na Europa as primeiras formulações teóricas sobre a restauração de monumentos. Compete destacar a figura pioneira de Viollet le Duc, com seu princípio de que "...qualquer forma deve ser explicada para ser bela" que se traduz na elaboração de um impressionante dicionário baseado na arquitetura francesa. Cabe também reconhecer o trabalho de John Ruskin, um apaixonado defensor da arte e da arquitetura medieval; de Camilo Sitte e sua especial atenção ao tratamento dos conjuntos e da composição urbana; e de Patrick Geddes pela sua reivindicação sobre a importância da forma geral da cidade.

No século XIX o Brasil ainda não possui uma discussão equivalente com respeito a preservação dos monumentos, mas podemos chamar de emblemático e inovador as primeiras políticas para preservar e manter as paisagens naturais vinculadas a cidade, medidas que até hoje orientam fortemente o urbanismo brasileiro. Ressalta-se a atuação de Don Pedro II, em 1860, que legisla sobre a criação de um parque envolvendo as Florestas da Tijuca e das Paineiras no Rio de 
Janeiro, por meio do qual se elabora o maior projeto de preservação e recuperação ambiental já realizado no mundo. Destaca-se o trabalho paisagístico do Barão d'Escragnolle, que concilia a preservação das florestas com espaços de uso público, com áreas culturais e de lazer, com desenhos de caminhos, fontes e lagos, que além de recuperar os componentes da paisagem natural da cidade garante a aproximação e o vínculo afetivo da população com o espaço natural.

Passado esse período, agora na entrada do século $\mathrm{XX}$, a sociedade brasileira espera ansiosa pela chegada da modernidade, buscando uma libertação frente aos modelos do período colonial. $\mathrm{O}$ anseio por tempos modernos se manifesta através das transformações morfológicas dos grandes centros urbanos, destacando-se os processos realizados no Rio de Janeiro, Niterói, Porto Alegre, Salvador, São Paulo e Recife. As reformas são antes de tudo um processo de embelezamento da antiga cidade colonial, que se faz pelo melhoramento das fachadas e da realização de obras urbanas, convergindo na modernização dos edifícios, na abertura de ruas e avenidas, largos e praças, e na produção de paisagismo.

Concomitante com as reformas que se realizam na virada do século, iniciam-se as primeiras reflexões em defesa do patrimônio brasileiro. O arquiteto e engenheiro Ricardo Severo, profere em 1914 a conferência chamada "A Arte Tradicional Brasileira", onde propõe a valorização das raízes nacionais que deve ser encontrada na cultura germinada no território a partir da chegada do homem Europeu. Trata-se da primeira inspiração nacionalista que fará fundo ao movimento Neocolonial brasileiro. Essas ideias se constituem também como base para a elaboração de outros eventos, que por fim culminam na realização da semana da Arte Moderna em 1922, onde Mário de Andrade atua como um dos maiores entusiastas. O evento representa uma verdadeira renovação de linguagem, uma busca por novas experimentações, pela liberdade criadora do modernismo brasileiro e fundamentalmente pela ruptura com o passado colonial, que agora pode ser pensado sem abandonar a identidade e a memória, que passa a ser representada e reconhecida através de seus monumentos históricos.

Na Europa, as destruições ocasionadas pela primeira Guerra Mundial, passam a direcionar as políticas para a preservação dos monumentos. Em 1931, G. Giovanini publica o primeiro livro centrado especificamente na proteção dos centros históricos. Não está bem avançado o século $X X$, ainda no calor das crises industriais e do crescente turismo cultural, quando se manifesta um apreço por uma concepção mais ampla de patrimônio, como legado de uma experiência e do esforço de uma comunidade. O patrimônio abandona o enfoque de 
mera concepção esteticista e restringida em tantos casos a monumentos arquitetônicos, para reinterpretar-se de uma maneira muito mais geral, como sendo $\neg$ lugar onde se produz a memória. Toma-se consciência de seu valor como herança da sociedade e de seu carácter indissolúvel com o patrimônio. Surgem com isto novas instituições, instrumentos e conceitos, como por exemplo as paisagens culturais.

\section{O SURGIMENTO E POSICIONAMENTO DO IPHAN NO BRASIL}

O Instituto de Patrimônio Histórico e Artístico Nacional (IPHAN) é uma autarquia federal que surgiu para preservar e proteger o patrimônio cultural, assegurando sua permanência e seu usufruto para as gerações presentes e futuras.

Interessa salientar, que desde o início da criação do Instituto IPHAN o órgão tem se preocupado em promover trabalhos pela defesa da genuína cultura brasileira, vislumbrando uma interpretação inovadora e ampla do conceito de patrimônio. Com foco nestas preocupações, destacam-se as atuações do ministro Gustavo Capanema, do poeta Mário de Andrade e do advogado Rodrigo Melo Franco de Andrade, que tiveram um papel importante na formação e consolidação do Instituto.

Na década de 1930, as iniciativas preservacionistas começam a florescer no Brasil. Em 1933, a cidade de Ouro Preto torna-se um monumento de expressão nacional, em reconhecimento pelo seu passado histórico e pelo grande significado de seu patrimônio edificado, que representa uma importante mostra da cultura brasileira. Neste contexto, em um certo paralelismo com Paris, surge a Inspeção Nacional de Monumentos, antecessor imediato do IPHAN. A entidade, vinculada ao Museu Nacional de História, começa a operar no ano de 1934, alinhada com a promulgação da nova constituição federal que incumbe à União, aos Estados e aos Municípios a proteção do patrimônio artístico e dos objetos de interesse histórico. Entre os objetivos principais, busca-se evitar a evasão das antiguidades brasileiras que são intensamente negociadas no comercio exterior, bem como, evitar a destruição dos patrimônios urbanos nos processos de inovação e modernização das cidades.

Três anos depois, em 1937, se regulamenta o trabalho do IPHAN (com a denominação inicial de SPHAN), tendo como presidente Rodrigo Melo Franco de Andrade, que permanece no 
posto durante trinta anos. Também é importante reconhecer o trabalho dos historiadores Afonso Arinos e Sergio Buarque de Holanda, e, fundamentalmente do arquiteto Lúcio Costa, que defende a necessária e enriquecedora convivência entre vestígios históricos e peças da nova arquitetura do Modernismo, a partir de um diálogo fecundo e dinâmico.

A convivência cultural entre arquiteturas de diferentes períodos e vários tipos de manifestações artísticas, marca o início dos trabalhos do IPHAN, que se esforça para documentar quaisquer vestígios de tradição, em uma postura bem diferente do que se observa na Europa do mesmo período. Na Europa podemos verificar uma interpretação marcadamente monumental do patrimônio, em uma absoluta ausência de diálogo, com escassas e honrosas exceções entre os conservacionistas e os paladinos da nova arquitetura. Basta recordar algumas das propostas mais emblemáticas dos principais arquitetos, como a do Plano Voisin de Paris em 1925, a cargo de Le Corbusier, que implica arrasar boa parte do coração da Marais (Louvre, Jardim das Tolherias, rua Rivoli, praça da Concorde e outros).

Convém destacar que o Plano Voisin é produzido na mesma época em que os arquitetos brasileiros modernistas estão encaixando primorosamente o Ministério da Saúde ao lado dos monumentos religiosos do entorno.

Ao longo de três quartos de século o IPHAN tem evoluído notavelmente, ajustando-se as mudanças e aos marcos legais da legislação brasileira. A concepção atual do patrimônio está respaldada na Constituição Federal de 1988, onde o legislador atribui grande abrangência ao conceito, definindo-o no artigo 216 , como formas de expressão, modos de criar, fazer e viver. Reconhecendo também as criações científicas, artísticas e tecnológicas; as obras, objetos, documentos, edificações e demais espaços destinados às manifestações artístico-culturais; e por fim, os conjuntos urbanos e sítios de valor histórico, paisagístico, artístico, arqueológico, paleontológico, ecológico e científico.

\section{DOS MONUMENTOS ÀS PAISAGENS CULTURAIS}

Podemos descobrir as origens do termo paisagem cultural nos escritos de historiadores ou geógrafos, alemães e franceses, do final do século XIX. Desde as alegações deterministas de Friedrich Ratzel; a atenção que Otto Schlütter que reclama a ideia de landschaft como uma 


\section{ID_EDITORIAL}

área definida pela inter-relação harmoniosa e uniforme de elementos físicos; e a interpretação da incidência mútua entre natureza e humanidade defendida por Vidal de la Blaché. Outros sociólogos e filósofos franceses (Emile Durkheim, Frédéric Le Play) defenderam a relação entre formas culturais de vida e territórios, associando em definitivo a paisagem com seus habitantes. Contudo, a aceitação atual sobre o conceito de paisagem cultural surge apenas no princípio do século XX.

É o professor Carl Sauer, que estuda na Alemanha e Chicago, quem propaga seu uso na Universidade de Berkeley na década de vinte. Revisando aquela primeira ideia de landschaft. Sauer aprofunda o que denomina geografia cultural, disciplina que analisa as transformações da paisagem natural, em cultural, produzida pela ação do ser humano, estudando a relação mútua entre o hábitat e os hábitos.

No texto "A morfologia da Paisagem" (1925), Sauer define paisagem cultural como o resultado da ação de um grupo cultural sobre uma paisagem natural. A cultura é o agente, o natural é o meio; a paisagem cultural é o resultado.

Sauer e os geógrafos da escola de Berkeley recompõem a ideia da paisagem como uma imagem composta a um território, um lugar concreto, caracterizado por uma cultura coerente e estável. E analisa como os elementos da paisagem vernácula se deslocam de um lugar a outro no território, identificando os padrões de migração cultural.

Sauer também nos fala que a paisagem cultural é o registro do homem sobre o território; em termos atuais podemos acrescentar que a paisagem é como um texto que pode ser escrito e interpretado, entendendo-a como uma construção humana.

Outra contribuição relevante para a difusão dos estudos sobre paisagens culturais será realizada pelo escritor e editor John Brinckerhoff Jackson, que compartilha com Sauer uma longa relação e correspondência. Brinckerhoff atua como conferencista e professor em diversas universidades onde ministra uma disciplina denominada Estudos da Paisagem. Mas talvez, o trabalho como editor da revista Landscape e como autor de numerosos artigos, tenha sido o seu legado de maior relevância. Brinckerhoff inicia a revista em 1951, inspirado em uma recém aparecida Revue de géographie humaine et d'ethnologie, e a promove durante mais de 17 anos, e continua colaborando, mesmo com outro editor, até sua morte em 1996. 
A revista arranca com traduções de trabalhos de diversos geógrafos franceses, que abordam a relação entre genre de vie e pays ( $O$ país e os modos de vida); abordando também outras visões da paisagem, desde perspectivas de historiadores, arquitetos, paisagistas, planificadores, sociólogos, geógrafos, antropólogos ou periodistas, que pretendem consolidar as bases da interpretação da paisagem cultural. Durante meio século seus artigos de arquitetura vernácula, planejamento urbano e rural, história americana, antropologia, geografia cultural, preservação e turismo, nutrem as páginas de uma publicação seminal e junto com suas aulas exercem uma extraordinária influência em sucessivas gerações de estudantes.

O extenso legado de Sauer e Brinckerhoff, mostra sobretudo uma visão analítica e operativa da paisagem cultural, recebe novos contornos no momento em que é retomada pela UNESCO, no fim do século XX, como uma categoria do Patrimônio Histórico, tendo uma preocupação mais administrativa, preservadora e política, do que acadêmica e projetual.

\section{E O CONCEITO DE PAISAGEM CULTURAL TORNA-SE OPERATIVO}

Embora tenha reconhecimento oficial, ainda hoje a Paisagem Cultural constitui-se como um termo pouco comum para um conceito relativamente opaco. Como exemplo temos as definições relativamente complexas que propõe a UNESCO, onde aprova em 1992 um instrumento de reconhecimento e proteção do patrimônio cultural de valor universal. Também não resulta mais esclarecedoras as categorias estabelecidas pela National Park Service, entidade que mais tem promovido e amparado as paisagens culturais.

Precisamos de uma definição um pouco mais fácil, e propomos a seguinte: a paisagem cultural é um âmbito geográfico que está associado a um evento, a uma atividade ou a um personagem histórico, que contém valores estéticos e culturais. Ou ainda, dito de uma maneira menos ortodoxa, porém simples e bonita, a paisagem cultural é a marca do trabalho sobre o território, algo como um memorial do trabalhador desconhecido. ${ }^{1}$

O que nos interessa destacar, é que os esforços para definir um conceito nascem de uma crescente preocupação com o patrimônio. A UNESCO celebra em 1972 uma convenção para a proteção do patrimônio natural e cultural, antecedente de sua política de paisagens culturais, que se cristaliza 20 anos depois, em 1992. Surgem em pouco tempo, impulsionadas por 


\section{ID_EDITORIAL}

comunidades locais, numerosas iniciativas que buscam o tratamento de amplos territórios com vestígios patrimoniais, produzindo uma gestão similar a dos grandes parques nacionais, embora com um componente sociocultural acrescentado.

No calor desta preocupação se desenvolve a arqueologia industrial na Inglaterra, França e Alemanha (estudo científico sobre o patrimônio industrial). Se inicia com os "palácios da indústria" (fase ilustre da indústria do século XIX), e rapidamente se estende às manifestações menos grandiosas ou singulares, em uma interpretação geral da paisagem industrial.

$\mathrm{Na}$ Europa essas iniciativas fixam-se em áreas de antiga industrialização, a partir do anseio pela sua reativação, promovendo não apenas a preservação do patrimônio, mas a educação, as atividades recreativas e o favorecimento do desenvolvimento económico.

Vale lembrar que o contexto brasileiro não se encontra distante nesta discussão. Podemos citar como exemplo, ainda no ano de 1977, a magnifica obra do Sesc Pompéia em São Paulo, projetada e executada pela arquiteta Lina Bo Bardi, que se preocupa em valorizar e dar novo sentido a uma antiga fábrica de tambores, gerando uma arquitetura marcante, com discussões importantes sobre a ressignificação de antigas peças urbanas, associando ideias de estética, plástica, uso público e funcionalidade.

$\mathrm{Na}$ Europa ocorre a recuperação de extensas paisagens industriais, como iniciativa que se fundamenta no estudo da reabilitação de elementos patrimoniais, e na sua utilização para atrair estudiosos e turistas. Surgem os denominados parques patrimoniais como estratégia de desenvolvimento territorial. Que se conduz por um processo metódico que compreende o inventário dos recursos, sua hierarquização, interpretação em função de uma determinada história e construção de uma estrutura suporte mediante itinerários que os vinculam entre si e entre os centros de interpretação, museus e serviços.

A Europa, e fundamentalmente a América, seguem produzindo cada vez mais projetos de parques industriais, mineiros, agrícolas, fluviais, percursos históricos, paisagens bélicas, parques arqueológicos e eco museus. E neste sentido encontramos magníficos exemplos latino-americanos.

O Caminho do Gaúcho, que se estende desde Laguna (Brasil) até o Mar do Prata na Argentina, atravessando o litoral de Uruguai. É uma iniciativa que articula um conjunto de 
recursos e serviços na temática de um território com histórias em comum, propondo recursos de revalorização para impulsar o desenvolvimento regional.

No mesmo sentido temos o caminho das estâncias jesuíticas ao redor de Córdoba (Argentina), já declarado como Patrimônio da Humanidade. Também temos o patrimônio de estâncias no norte da Argentina, Paraguai e Brasil; os inúmeros territórios mineiros do Chile; o impressionante conjunto natural e cultural de Minas Gerais; os territórios do salitre; o projeto do caminho de Humboldt, na Venezuela; ou ainda as muitas paisagens culturais brasileiras que estão pouco a pouco se valorizando no país.

Em uma análise dos projetos mais significativos nos Estados Unidos, Europa e Latino-américa, podemos extrair uma primeira conclusão: a gestão inteligente dos recursos patrimoniais supõe em diversos territórios um fator propulsor do desenvolvimento econômico, porque atrai turismo e inversões, gera atividades e postos de trabalho, mas fundamentalmente, porque reforça a autoestima de sua comunidade. Isso nos leva a pensar, que os sintomas de aparente debilidade dos cenários em crise, podem ocultar a chave para uma futura transformação. As mostras de decadência e os vestígios de um esplendor passado, podem ser interpretados como uma condenação para os territórios, ou então, podem ser pensados como um ativo para construir um novo futuro, valorizando e estruturando os recursos disponíveis, convergindo-os em uma base adequada para a sustentação de um novo desenvolvimento.

\section{POR UMA INTERPRETAÇÃO DAS PAISAGENS CULTURAIS DO BRASIL}

Não obstante a história do IPHAN, em reconhecer os contextos culturais do patrimônio, a categoria de Paisagem Cultural só começa a operar definitivamente no Brasil a partir da Portaria $n^{\circ} 27 / 2009$, que define o conceito e regulamenta a chancela como novo instrumento de proteção dos patrimônios identificados como paisagens culturais.

A portaria define a Paisagem Cultural como sendo uma porção peculiar do território brasileiro, representativa de um processo de interação do homem com o meio natural, à qual a vida e a ciência humana imprimem marcas ou atribuem valores.

A chancela da Paisagem Cultural Brasileira traz como inovação uma política de convivência entre o patrimônio e o caráter dinâmico da cultura e da ação humana. A finalidade do 


\section{ID_EDITORIAL}

instrumento da chancela é conviver com as transformações inerentes ao desenvolvimento econômico e social, incentivando e direcionando iniciativas sustentáveis para amparar os contextos onde se inserem as paisagens culturais.

A aplicação deste instrumento impõe ao IPHAN desafios cada vez mais complexos, que vem se posicionando como um órgão mediador no estabelecimento de pactos de gestão compartilhada, envolvendo não apenas o poder público, mas a sociedade civil, as entidades e a iniciativa privada.

Este número da revista Identidades pretende modestamente contribuir para o melhor conhecimento de algumas paisagens culturais no Brasil, mas conscientes de que estamos tratando de um país de riqueza cultural extraordinária e diversificada, sendo impossível cobrir em uma seleção de textos, por mais amplo que seja. Também é verdade, que nem todas essas paisagens foram suficientemente estudadas, nem colocadas em valor e à serviço de sua comunidade.

Assim, para esta edição especial da revista, tentamos selecionar exemplos, no desejo de que eles sejam suficientemente representativos. Tendo em conta os limites razoáveis de extensão, busca-se contribuições de paisagens culturais diversas, desde aquelas já reconhecidas, a outras apenas consideradas; sublimes ou cotidianas; agrícolas ou industriais; permanentes ou efêmeras. Apresentando uma reflexão sobre os desafios da gestão e as fragilidades frente aos processos de globalização e universalização da cultura.

Este número também representa o esforço de investigadoras e investigadores, para o estudo e salvaguarda destas paisagens culturais. Estudiosos e também agentes locais, que, seguindo o exemplo pioneiro de Mário de Andrade e Gilberto Freyre, têm documentado os vestígios da tradição e as paisagens do trabalho de gerações que nos precederam, como testemunho de respeito ao território, a cultura e a sociedade.

Os trabalhos refletem um país multicultural de muitas manifestações e paisagens exuberantes. Trata-se de um Brasil de muitas histórias, técnicas e saberes, que foram se produzindo pela experiência do homem e pelo conhecimento do território, que contempla a riqueza de seu solo, suas matas, seus rios, seus minérios e todos os elementos que dinamizam a vida dos grupos humanos. Um Brasil de muitos cenários, que possui um patrimônio vivo, vibrante e representativo.

Os textos apresentados respondem a diferentes perspectivas e enfoques, desde visões oficiais e reconhecidas, baseadas em métodos tradicionais do processo de inventário e 
tombamento, na pretensão de uma etiqueta de reconhecimento universal; a outras visões mais exploratórias, seguramente mais arriscadas, contudo em consonância com as últimas abordagens internacionais na temática de paisagens culturais.

Iniciamos a apresentação dos artigos com esses textos mais exploratórios, que se focam em recursos patrimoniais aparentemente modestos, pouco estudados, que nos remetem a ideia de paisagem cultural como resultado do trabalho humano sobre o território, fixando-se em recursos tangíveis ou intangíveis que caracterizam as culturas e as tradições. E o fazem, muitas vezes, para ir além de reclamar sua mera preservação, mas para revalorizá-los, para defender a sua essência e aceitar a sua transformação, sempre que esta suponha a vontade de acomodar-se ao tempo de seus construtores, na tentativa de que isto proporcione uma vida com maior dignidade.

A partir destas motivações, os autores abordam diferentes etapas no processo de percepção e gestão, apresentando alternativas de fontes de investigação, métodos de análise e experiências de intervenção, que por vezes se apresentam bem-sucedidas e por outras não tão bem, que podemos observar a seguir, representadas na descrição da paisagem cultural mineira, caipira, imigrante, ribeirinha, ferroviária, japonesa, rural e urbana.

Vanessa Bello e Andrey Schlee expõem as ações do IPHAN para responder as novas condições impostas pelo aumento da participação cidadã e da evolução do conceito de patrimônio cultural. Desde 2009 o IPHAN conta com a Chancela da Paisagem Cultural como instrumento para a proteção do patrimônio, possibilitando segundo os autores a incorporação da cidadania, por meio de diálogos entre órgãos de preservação, sociedade organizada e demais agentes institucionais, organizando ações conjuntas de gestão e defesa do patrimônio cultural.

Flávia Brito e Simone Scifoni, trazem um artigo que representa os diversos processos de imigração no Brasil, tratam especificamente do reconhecimento da paisagem cultural japonesa no vale do Ribeira. Através de fontes históricas, identificam como o grupo cultural consegue adaptar suas técnicas e imprimir marcas de seu trabalho na paisagem, que vão desde a arquitetura das habitações, as plantações de chá, o trabalho com junco, passando pela própria história da cidade de Registro e pela Festa do Tooro Nagashi.

Nesse mesmo sentido, Vanessa Figueiredo expõe a magnifica paisagem cultural de Paranapiacaba, que corresponde a uma vila ferroviária implantada no topo da Serra do Mar, construída a partir de 1860 pela companhia inglesa São Paulo Railway. Neste contexto, 


\section{ID_EDITORIAL}

ambiental, patrimonial e cultural, apresenta uma experiência bem-sucedida entre a integração de políticas de preservação e o melhoramento da qualidade de vida da população local.

Jane Victal e Adelita Araujo, apresentam a paisagem cultural do Alto Vale do Paraíba, formada por uma identidade típica da cultura paulista - o Caipira. O artigo recorre a fontes históricas recompondo a ocupação do território para entender sua organização e o uso dos seus elementos naturais. A abordagem está relacionada com a longa tradição do cultivo do milho, em uma região de pequenos morros, vales e rios. O padrão entrelaçado das pequenas cidades, da arquitetura, dos bairros rurais, dos significados simbólicos e das tradições festivas, ilustra cada faceta dessa produção e desse modo de vida, que tem sido vivenciado a pelo menos dois séculos e necessita de novas perspectivas para continuar a se reproduzir.

Maria Regina Weissheimer mostra a singular paisagem cultural da imigração em Santa Catarina, onde se destacam grupos italianos, alemães e eslavos. Em cada contexto a autora afirma a adaptação do imigrante às condições naturais do território, onde desenvolvem soluções locais com características peculiares de instalação, propriedade rural, indústria familiar, produção arquitetônica, cultivo da terra e tradições. A autora observa ainda, que a partir da segunda metade do século $\mathrm{XX}$, com a crescente industrialização e a rápida transformação das cidades, o produto artesanal, produzido pelos imigrantes, perde espaço comercial, sendo necessário a preservação dos aspectos autênticos da paisagem como alternativa econômica para o sustento dessas pequenas propriedades.

Luís Antônio Jorge descreve a encantadora paisagem cultural do sertão de Minas, onde através de fontes literárias, obtidas pelos contos do poeta João Cabral de Melo Neto e do escritor João Guimarães Rosa, nos remete aos cenários da vida cotidiana e do trabalho com o carro de boi. Em uma pesquisa de campo, que envolveu paciência e dedicação, acompanhou por mais de um ano o processo de confecção de um carro de boi. Esse estudo, não apenas reconhece essa paisagem cultural, mas idealiza a reabilitação de um espaço cultural no Morro da Garça, local descrito nos contos de Guimarães Rosa e que celebra eventos regulares dedicados ao autor e a paisagem cultural do carro de boi.

Flavio Carsalade faz uma reflexão sobre as Paisagens Culturais da Mineração no estado de Minas Gerais. Reivindicando um resgate do papel articulador do Estado, que necessita impor uma gestão mais ativa no território, deixando de atuar apenas como um agente regulador dos 
interesses privados. A partir disso, propõe a criação do Geoparque do Quadrilátero Mineiro, para integrar os sítios de mineração, não apenas no propósito da sustentabilidade, mas como indutor de uma dinâmica territorial que envolva uma visão de futuro e um plano de desenvolvimento para a paisagem.

André Argollo propõe uma nova abordagem nas paisagens culturais, a partir de sistemas territoriais integrados e a paisagem rural do Brasil, que se caracteriza pela coexistência de cadeias produtivas simples e pouco integradas com os complexos produtivos altamente tecnificados e integrados com a indústria, o comércio e o setor de serviços. Traz como método uma visão sistêmica, que permitirá observar as nuances que caracterizam a heterogeneidade e a riqueza da arquitetura rural e agrícola, bem como idealizar um planejamento sustentável no território.

Leonardo Castriota traz o caso da cidade do Serro, que se tornou um dos primeiros conjuntos urbanos a ser tombado nacionalmente pelo IPHAN no ano de 1938. O Serro apresenta um excepcional conjunto arquitetônico, ao lado de fortes elementos naturais como a Serra do Espinhaço, as matas e sítios arqueológicos. A cidade possui bens culturais imateriais de grande importância, ligados tanto à religiosidade, quanto à sua longa tradição rural, tais como o conhecido "Queijo do Serro", registrado como patrimônio nacional em 2008. O autor analisa o plano de revitalização da paisagem cultural, através da chamada agricultura urbana, que atualmente se encontra em curso na cidade e parte da compreensão de seu caráter rural e de sua conformação morfológica.

Rafael Ribeiro demonstra a Paisagem Cultural Urbana da cidade do Rio de Janeiro, onde analisa como essa tipologia de paisagem cultural vem sendo abordada e utilizada. Segundo o autor, a paisagem urbana tem sido foco de uma visão vinculada a ideia de centro histórico, impedindo a leitura de importantes áreas que não se enquadram nesse conceito. $O$ autor alerta, que muitas áreas localizadas fora dos centros históricos constituem-se como referência de significado, tanto para a cidade quanto para determinados grupos humanos, sendo imprescindível o seu reconhecimento e a sua valoração.

Marcelo Brito e Ana Clara Giannecchini, analisam os novos desafios, cada vez mais complexos, que põem em xeque a capacidade de resposta do Instituto do Patrimônio Histórico

e Artístico Nacional (IPHAN). Para isso nos apresentam a Paisagem Cultural das Missões 


\section{ID_EDITORIAL}

Jesuíticas Guaranis, repensando sua proteção a partir de uma visão sistêmica, que envolve o reconhecimento da paisagem cultural e o abandono de práticas que tratam o patrimônio como um conjunto de bens culturais isolados, respeitando suas referências e suas tradições culturais, para atingir sua preservação e seu desenvolvimento local.

Mónica Mongelli, exibe a metodologia aplicada pelo IPHAN para reconhecimento da paisagem cultural da foz do rio São Francisco. A partir de entrevistas e inventários, busca compreender os valores que são atribuídos à paisagem cultural, delimitando uma porção territorial e selecionando bens representativos associados às práticas e manifestações estudadas, como por exemplo uma canoa de corrida e o modo de fazer artesanato em palha.

Virgínia Karla de Souza busca a valorização da paisagem cultural de Pitimbu na Paraíba, que se caracteriza especialmente pela técnica de construção de uma embarcação tradicional conhecida como "jangada de duas velas". O artigo traz uma reflexão baseada em fontes documentais, que identificam as ameaças para a continuidade desta paisagem. Segundo a autora esta paisagem sofre com os problemas ambientais e também com a expansão urbana desordenada, especulação imobiliária e deficiência de planejamento territorial, problemas que devem ser identificados para gerar soluções e estratégias mais adequadas e eficientes para o local.

Mônica Mongelli e Andrey Schlee apresentam uma metodologia desenvolvida pelo IPHAN para caracterizar e descrever os Jardins Históricos do Brasil, que utiliza fichas de inventário e um sistema operacional, que permite a criação de uma rede geo-referenciada sobre os bens tombados, esperando obter maior controle e promoção de sua preservação.

\section{PAISAGENS QUE CONSTROEM IDENTIDADES}

A palavra cultura vem do latim colere e significa cultivar. Ação que historicamente possibilita a fixação do homem ao território, sua relação com o meio e o desenvolvimento das civilizações e das paisagens culturais. Dessa relação emanam as formas, materiais e imateriais, de um mundo humano e coletivo, carregadas de sentido e significados da experiência, que de maneira tão adaptada nos oferece uma sensação de harmonia e estética. É nessas formas que se apoiam as identidades, onde se estimula a criatividade, se explica a existência e se institui os modos de vida. São paisagens que constroem identidades. 
A maior parte dos planos de ordenação do século XX salientam a dinâmica populacional no desenvolvimento industrial, e utilizam a zonificação e o projeto de grandes infraestruturas como instrumento fundamental. Hoje, algumas propostas de ordenação territorial de notável interesse, começam a atender a um novo binômio: natureza e cultura. Natureza e cultura como partes de um conceito único: patrimônio. $\mathrm{E}$ as paisagens culturais podem constituir-se como um veículo para alcançar os objetivos de construir entornos mais diversos e carregados de identidade.

Neste sentido, devemos orientar nossos esforços em situar a paisagem como eixo central dos instrumentos e planos de ordenação. Paisagem em seu sentido mais amplo, natural e cultural. Paisagem não como resultado acabado de uma cultura, mas como realidade continuamente evolutiva. Assim, a herança cultural não deve ser interpretada simplesmente para preservar, pois, como temos visto, a paisagem cultural pode gerar oportunidades de desenvolvimento, coexistindo com valores históricos e novos valores territoriais. Se trata de superar uma posição meramente conservacionista do patrimônio e trabalhar com os recursos dentro dos processos de transformação. A construção de hoje que também pode gerar identidades e patrimônio para o amanhã.

É antes de tudo uma questão de posicionamento, de ver e avaliar as realidades em sua totalidade, a partir do mundo das pessoas e dos processos que as constituem. É pensar o patrimônio para a comunidade, transformando atores da preservação em atores do desenvolvimento, capazes não apenas de preservar, mas de produzir ações em benefício da população.

José Saramago, ilustríssimo escritor, e acima de tudo um grande ser humano, nos ensinou muitas coisas, uma das últimas na ilha de Lançarote, onde residia parte do ano, pouco antes de sua morte. Referindo-se a uma intervenção que iria afetar uma rica paisagem cultural La Geria, Saramago declarou, também como uma forma de alerta, que uma sociedade que não respeita o seu território (e podemos acrescentar o rico legado do esforço humano acumulado sobre este território), é uma sociedade que não respeita a si mesma.

Assim, aprendamos a respeitar o rico e diverso conjunto de paisagens culturais do Brasil, a valorizá-los e colocá-los a serviço da melhor qualidade de vida de seus moradores. Esta é a melhor mostra de respeito que podemos produzir. 